\title{
A review and visionary design of human tissue blood serum based low pass filter circuit for disease detection
}

\author{
M. S. Manavadaria ${ }^{\# 1}$, S. P.Kosta ${ }^{* 2}$ and V. P. Tank ${ }^{\# 3}$ \\ \#EC Department, CSPIT, CHARUSAT, Changa, Pin-388421, Ta.-Petlad, Dist.-Anand, Gujarat, INDIA \\ ${ }^{1}$ manthanmanavadaria.ec@charusat.ac.in \\ 3vishaltank.ec@charusat.ac.in \\ ${ }^{*}$ CSTC, CHARUSAT, Changa, Pin-388421, Ta.-Petlad, Dist.-Anand, Gujarat, INDIA \\ 2drspkosta@yahoo.com
}

\begin{abstract}
A "Filter" is very common terminology used by electronic circuit design engineer for implementing various circuits and system. General understanding of filter itself indicate that it removes unwanted part of input data. This concept has been developed in analog filter as well as in digital filter. It is also used in designing of medical instrumentation that used for various diseases diagnostic. The medical treatment of patient and working of instruments is combining at the point we can called sensor. Electronics in medicine has a wide range of applications, from diagnostics to therapy, always aiming to provide new tools to improve the well-being of the population. Moreover, some blood taste also working on the concept of filtering. The fundamental electronic component's characteristic has been already observed in human tissues like blood serum, skin etc. By combining filter concept with these human tissue components, we have achieved specific characteristics as a result of our experiments. This article indicates the important behaviour and realisation technique for such bio-electronics filter. It is also helpful to understand biological signal analysis. Additionally comparison of electronic filter and serum filter is represented in result section.
\end{abstract}

Keyword- Bio-electronics, Liquid State Electronics, Biological signal analysis and low pass filter.

\section{INTRODUCTION}

In Electronic System, use of filter is very common. The detail functioning, technical parameter and designing of various filter starting from vary simple low pass filter with first order to microwave filter are easily available as well as understandable from engineering references. There are many advanced software which provides the facility of filter designing and analysis of it like GENESYS, WEBENCH, FilterCAD etc. For this experiment all these technical details are not required so just brief about fundamentals of filter explained in next section.

Today medical science has grown up so much with basis of available medicine and treatment methodologies. The Bio-medical engineering and biotechnology are always helpful branches to develop this level till at better position. In addition to this are electronics science and engineering are core stream for this grownup. The latest technology for laparoscopy, sonography, X-Ray, ECG etc has increase the importance of this knowledge. Human body tissue based experiments is also going on in this era. A brief notes for such practical with published result is mentioned in latter section. After that experiment setup for low pass first order filer using sample of human blood serum is presented. For accuracy and precession of readings, result section is given with graph as well as in tabular data form. A short conclusion indicates important of this study with analysis of comparison of ideal electronic filter and human tissue based filter.

Before submitting your final paper, check that the format conforms to this template. Specifically, check the appearance of the title and author block, the appearance of section headings, document margins, column width, column spacing and other features.

\section{FUNDAMENTALS OF FILTER}

Basically, an electrical filter is a circuit that can be designed to modify, reshape or reject all unwanted frequencies of an electrical signal and accept or pass only those signals wanted by the circuit designer. In low frequency applications, passive filters are generally constructed using simple Resistor Capacitor (RC) networks, while higher frequency filters are usually made from Resistor-Inductor-Capacitor (RLC) components. The output is always less than the input because filters have no gain or no amplifying components. They are known according to the frequency range of signals that they allow to pass through them, while blocking or attenuating the rest. The most commonly used filters designs are as below:

The Low Pass Filter - the low pass filter only allows low frequency signals from $0 \mathrm{~Hz}$ to its cut-off frequency to pass while blocking those any higher. 
The High Pass Filter - the high pass filter only allows high frequency signals from its cut-off frequency and higher to infinity to pass through while blocking those any lower.

The Band Pass Filter - the band pass filter allows signals falling within a certain frequency band setup between two points to pass through while blocking both the lower and higher frequencies either side of this frequency band.

As the function of any filter is to allow signals of a given band of frequencies to pass unaltered while attenuating or weakening all others those are not wanted, we can define the amplitude response characteristics of an ideal filter by using an ideal frequency response curve of the basic filter types as shown below.
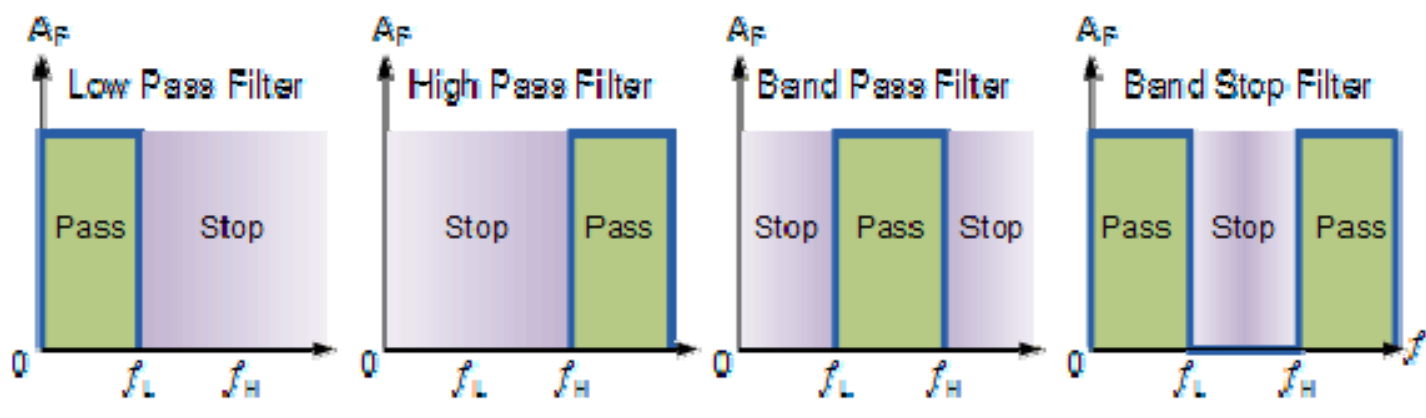

Figure 1: Frequency response of basic filters ${ }^{[13]}$

Simple first order passive filters can be made by connecting together a single resistor and a single capacitor in series across an input signal with the output of the filter taken from the junction of these two components as indicated in below figure. Depending on which way around we connect the resistor and the capacitor with regards to the output signal determines the type of filter construction resulting in either a Low Pass Filter or a High Pass Filter. In this experiment below circuit is implemented using electronic component as well as serum.

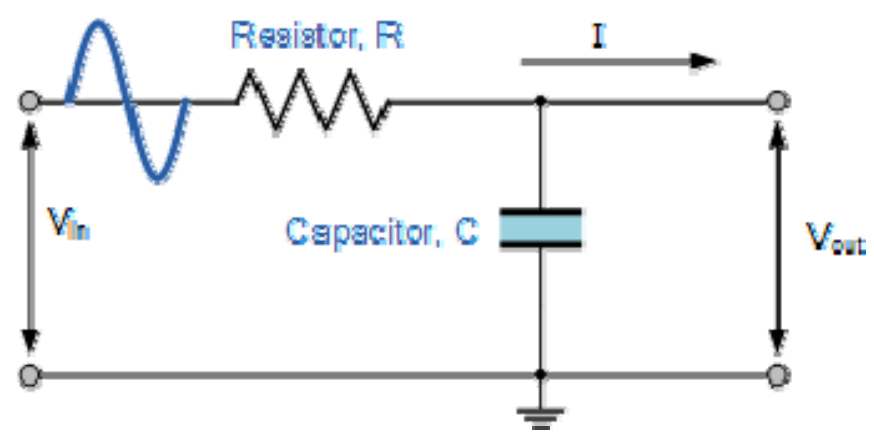

Figure 2: First order low pass RC filter ${ }^{[13]}$

\section{III.HUMAN TISSUE BASED ELECTRONICS}

Today, the Medical Engineering is well known stream for innovation. Since last decade, very fast change occurs in related field known as Bio-Medical Engineering. More or less it's deals with medical instrumentation for diagnostic and analysis for various human's characteristics and behaviour. Recently Bio-Electronics field also become popular to perform the same task with help of combining electronics knowledge in addition with medical engineering. Artificial body parts with sensor, pacemaker, hearing machine etc are well known examples of this. At very deep level human tissue based electronic analysis also done. Such experiments indicated common characteristics of basic electronic components diode and transistor using human body tissues like human blood or skin. It is also experimented tree's leaf and resulted successful experiment in green bio mass also. Few of results and experiment setup is shown in below figures.

The result of this referenced article giving clear cut indication that there will be different characteristics for every different human bodies. Again it is also depend on various parameters like temperature of human body, stress level, health condition, environment of testing place, sensor or probes and many more. The very interesting thing is, after all such dependency according to design circuit human body will provide some specific characteristic. The latest technology and upcoming instruments are based on such results only. This thought results into one more experiment based on Passive Filter based on human body tissue blood serum. 


\section{IV.SERUM BASED FILTER}

The Liquid State Electronics (LSE) is still subject of research compare to Solid State Electronics (SSE). The represented concept in this article is also opens idea about LSE technique. We have considered resistor and capacitor characteristics can be found in human blood serum with proper arrangements and sensing technique. A resistor and a capacitor is considered in two different test tube as per below figure. Specific and sufficient amount of serum sample is taken into test tubes. The each human body has different characteristics, so instead of taking only one type of serum, sample is form with three different combinations of serum contents (in form of density of serum). The proportionality is indicated in below table. Based on this with different water level 1, 1.2 and 1.5 litters we have taken serum 1 (S1), Serum 1.2 (S1.2) and Serum 1.5 (S1.5).

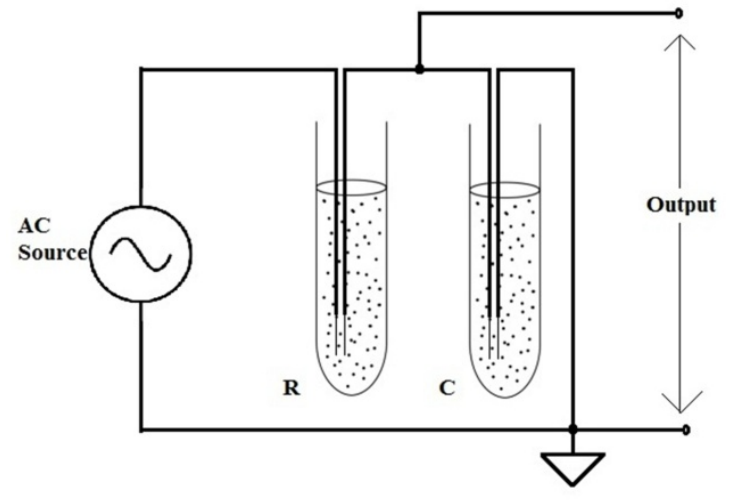

Figure 3: Serum based filter

Table 1: Serum Sample Composition

\begin{tabular}{|c|c|c|c|}
\hline $\begin{array}{c}\text { Serum Sample } \\
\text { Content }\end{array}$ & $\begin{array}{c}\text { Molecular Wight } \\
\text { (gm/mol) }\end{array}$ & $\begin{array}{c}\text { Proportional } \\
\text { level }\end{array}$ & $\begin{array}{c}\text { Effective Molecular } \\
\text { weight (gm/mol) }\end{array}$ \\
\hline $\mathrm{NaCl}$ & 58.44 & 0.1 & 5.844 \\
\hline $\mathrm{KCl}$ & 74.55 & 0.05 & 3.7275 \\
\hline $\mathrm{CaCl}$ & 110.98 & 0.05 & 5.549 \\
\hline $\mathrm{MgSO}_{4}$ & 120.36 & 0.05 & 6.018 \\
\hline $\mathrm{NaHCO}_{3}$ & 84.007 & 0.05 & 4.20035 \\
\hline $\mathrm{Na}_{2} \mathrm{HPO}_{4}$ & 141.96 & 0.05 & 7.098 \\
\hline
\end{tabular}

As indicated in figure simple copper cable is used as connecting medium between serum and electronic circuit. The input ac signal is fix in terms of amplitude that is $10 \mathrm{Vp}-\mathrm{p}$. As per filter concept frequency is vary from $10 \mathrm{~Hz}$ to $10 \mathrm{MHz}$. The output is taken across " $\mathrm{C}$ " test tube, where $\mathrm{C}$ means considering that tube as capacitor. In same manner "R" indicate Resistor Test tube. The experiment is repeated three times with S1, S1.2 and S1.5. The obtained result is represented in next section using tabular as well as graph form. Few Oscilloscope images are also represented for characteristics learning of input and output signal.

\section{RESULtS}

Table 2: Serum based filter readings for $\mathrm{Hz}$ to $\mathrm{KHz}$ frequency range

\begin{tabular}{|c|c|c|c|c|c|c|c|c|}
\cline { 4 - 9 } \multicolumn{4}{c|}{} & \multicolumn{2}{c|}{ Serum-1 } & \multicolumn{2}{c|}{ Serum-1.2 } & \multicolumn{2}{c|}{ Serum-1.5 } \\
\hline Sr. no. & Freq.(Hz) & I/P (V) & O/P( V) & Gain & O/P (V) & Gain & O/P (V) & Gain \\
\hline 1 & 10 & 10.00 & 4.72 & 0.47 & 4.48 & 0.45 & 5.28 & 0.53 \\
\hline 2 & 20 & 10.00 & 4.72 & 0.47 & 4.48 & 0.45 & 5.28 & 0.53 \\
\hline 3 & 30 & 10.00 & 4.64 & 0.46 & 4.48 & 0.45 & 5.20 & 0.52 \\
\hline 4 & 40 & 10.00 & 4.56 & 0.46 & 4.40 & 0.44 & 5.20 & 0.52 \\
\hline 5 & 50 & 10.00 & 4.56 & 0.46 & 4.40 & 0.44 & 5.20 & 0.52 \\
\hline 6 & 60 & 10.00 & 4.56 & 0.46 & 4.80 & 0.48 & 5.20 & 0.52 \\
\hline 7 & 70 & 10.00 & 4.48 & 0.45 & 4.72 & 0.47 & 5.20 & 0.52 \\
\hline 8 & 80 & 10.00 & 4.48 & 0.45 & 4.72 & 0.47 & 5.12 & 0.51 \\
\hline 9 & 90 & 10.00 & 4.40 & 0.44 & 4.72 & 0.47 & 5.12 & 0.51 \\
\hline
\end{tabular}




\begin{tabular}{|c|c|c|c|c|c|c|c|c|}
\hline 10 & 100 & 10.00 & 4.40 & 0.44 & 4.72 & 0.47 & 5.12 & 0.51 \\
\hline Sr. no. & Freq.(Hz) & I/P V & $\mathbf{O} / \mathbf{P} \mathbf{V}$ & Gain & $\mathbf{O} / \mathbf{P} \mathbf{V}$ & Gain & $\mathbf{O} / \mathbf{P} \mathbf{V}$ & Gain \\
\hline 11 & 100 & 10.00 & 4.40 & 0.44 & 4.72 & 0.47 & 5.12 & 0.51 \\
\hline 12 & 200 & 10.00 & 4.40 & 0.44 & 4.56 & 0.46 & 4.96 & 0.50 \\
\hline 13 & 300 & 10.00 & 4.40 & 0.44 & 4.48 & 0.45 & 4.80 & 0.48 \\
\hline 14 & 400 & 10.00 & 4.32 & 0.43 & 4.48 & 0.45 & 4.72 & 0.47 \\
\hline 15 & 500 & 10.00 & 4.32 & 0.43 & 4.48 & 0.45 & 4.64 & 0.46 \\
\hline 16 & 600 & 10.00 & 4.32 & 0.43 & 4.48 & 0.45 & 4.72 & 0.47 \\
\hline 17 & 700 & 10.00 & 4.32 & 0.43 & 4.48 & 0.45 & 4.72 & 0.47 \\
\hline 18 & 800 & 10.00 & 4.24 & 0.42 & 4.40 & 0.44 & 4.64 & 0.46 \\
\hline 19 & 900 & 10.00 & 4.24 & 0.42 & 4.40 & 0.44 & 4.64 & 0.46 \\
\hline 20 & 1000 & 10.00 & 4.24 & 0.42 & 4.40 & 0.44 & 4.64 & 0.46 \\
\hline Sr. no. & Freq.(KHz) & I/P V & $\mathbf{O} / \mathbf{P ~ V}$ & Gain & $\mathbf{O} / \mathbf{P} \mathbf{V}$ & Gain & $\mathbf{O} / \mathbf{P} \mathbf{V}$ & Gain \\
\hline 21 & 1 & 10.00 & 4.24 & 0.42 & 4.40 & 0.44 & 4.64 & 0.46 \\
\hline 22 & 2 & 10.00 & 4.16 & 0.42 & 4.16 & 0.42 & 4.64 & 0.46 \\
\hline 23 & 3 & 10.00 & 4.16 & 0.42 & 4.00 & 0.40 & 4.56 & 0.46 \\
\hline 24 & 4 & 10.00 & 4.08 & 0.41 & 4.16 & 0.42 & 4.48 & 0.45 \\
\hline 25 & 5 & 10.00 & 4.08 & 0.41 & 4.16 & 0.42 & 4.48 & 0.45 \\
\hline 26 & 6 & 10.00 & 4.08 & 0.41 & 4.16 & 0.42 & 4.40 & 0.44 \\
\hline 27 & 7 & 10.00 & 4.08 & 0.41 & 4.08 & 0.41 & 4.32 & 0.43 \\
\hline 28 & 8 & 10.00 & 4.08 & 0.41 & 4.00 & 0.40 & 4.32 & 0.43 \\
\hline 29 & 9 & 10.00 & 4.16 & 0.42 & 4.00 & 0.40 & 4.32 & 0.43 \\
\hline 30 & 10 & 10.00 & 4.16 & 0.42 & 4.00 & 0.40 & 4.32 & 0.43 \\
\hline
\end{tabular}

Table 3: Serum based filter readings for $\mathrm{KHz}$ to $\mathrm{MHz}$ frequency range

\begin{tabular}{|c|c|c|c|c|c|c|c|c|}
\cline { 5 - 9 } \multicolumn{2}{c}{} & \multicolumn{2}{c|}{ Serum-1 } & \multicolumn{2}{c|}{ Serum-1.2 } & \multicolumn{2}{c|}{ Serum-1.5 } \\
\hline Sr. no. & Freq.(KHz) & I/P V & O/P V & Gain & O/P V & Gain & O/P V & Gain \\
\hline 31 & 10 & 10.00 & 4.16 & 0.42 & 4.00 & 0.40 & 4.32 & 0.43 \\
\hline 32 & 20 & 10.00 & 4.16 & 0.42 & 3.68 & 0.37 & 4.08 & 0.41 \\
\hline 33 & 30 & 10.00 & 4.32 & 0.43 & 3.68 & 0.37 & 3.92 & 0.39 \\
\hline 34 & 40 & 10.00 & 4.32 & 0.43 & 3.60 & 0.36 & 3.76 & 0.38 \\
\hline 35 & 50 & 10.00 & 4.32 & 0.43 & 3.60 & 0.36 & 3.76 & 0.38 \\
\hline 36 & 60 & 10.00 & 4.32 & 0.43 & 3.60 & 0.36 & 3.76 & 0.38 \\
\hline 37 & 70 & 10.00 & 4.40 & 0.44 & 3.56 & 0.36 & 3.76 & 0.38 \\
\hline 38 & 80 & 10.00 & 4.40 & 0.44 & 3.60 & 0.36 & 3.76 & 0.38 \\
\hline 39 & 90 & 10.00 & 4.40 & 0.44 & 3.60 & 0.36 & 3.76 & 0.38 \\
\hline 40 & 100 & 10.00 & 4.40 & 0.44 & 3.60 & 0.36 & 3.76 & 0.38 \\
\hline Sr. no. & Freq.(KHz) & I/P V & O/P V & Gain & O/P V & Gain & O/P V & Gain \\
\hline 41 & 100 & 10.00 & 4.40 & 0.44 & 3.76 & 0.38 & 3.76 & 0.38 \\
\hline 42 & 200 & 10.00 & 4.32 & 0.43 & 3.60 & 0.36 & 3.68 & 0.37 \\
\hline 43 & 300 & 10.00 & 4.24 & 0.42 & 3.76 & 0.38 & 3.68 & 0.37 \\
\hline 44 & 400 & 10.00 & 4.16 & 0.42 & 3.68 & 0.37 & 3.68 & 0.37 \\
\hline 45 & 500 & 10.00 & 4.00 & 0.40 & 3.60 & 0.36 & 3.40 & 0.34 \\
\hline 46 & 600 & 10.00 & 3.84 & 0.38 & 3.60 & 0.36 & 3.40 & 0.34 \\
\hline 47 & 700 & 10.00 & 3.76 & 0.38 & 3.60 & 0.36 & 3.32 & 0.33 \\
\hline 48 & 800 & 10.00 & 3.76 & 0.38 & 3.60 & 0.36 & 3.44 & 0.34 \\
\hline 49 & 900 & 10.00 & 3.76 & 0.38 & 3.60 & 0.36 & 3.44 & 0.34 \\
\hline 50 & 1000 & 10.00 & 3.76 & 0.38 & 3.60 & 0.36 & 3.40 & 0.34 \\
\hline
\end{tabular}




\begin{tabular}{|c|c|c|c|c|c|c|c|c|}
\hline Sr. no. & Freq.(MHz) & I/P V & O/P V & Gain & O/P V & Gain & O/P V & Gain \\
\hline 51 & 1 & 10.00 & 3.76 & 0.38 & 3.52 & 0.35 & 3.40 & 0.34 \\
\hline 52 & 2 & 10.00 & 3.68 & 0.37 & 3.36 & 0.34 & 3.40 & 0.34 \\
\hline 53 & 3 & 10.00 & 3.92 & 0.39 & 3.52 & 0.35 & 3.44 & 0.34 \\
\hline 54 & 4 & 10.00 & 4.16 & 0.42 & 3.52 & 0.35 & 3.60 & 0.36 \\
\hline 55 & 5 & 10.00 & 4.40 & 0.44 & 3.84 & 0.38 & 3.84 & 0.38 \\
\hline 56 & 6 & 10.00 & 4.72 & 0.47 & 3.76 & 0.38 & 3.84 & 0.38 \\
\hline 57 & 7 & 10.00 & 4.68 & 0.47 & 3.76 & 0.38 & 3.84 & 0.38 \\
\hline 58 & 8 & 10.00 & 5.44 & 0.54 & 3.76 & 0.38 & 3.84 & 0.38 \\
\hline 59 & 9 & 10.00 & 6.32 & 0.63 & 3.76 & 0.38 & 3.84 & 0.38 \\
\hline 60 & 10 & 10.00 & 7.20 & 0.72 & 3.76 & 0.38 & 3.84 & 0.38 \\
\hline
\end{tabular}

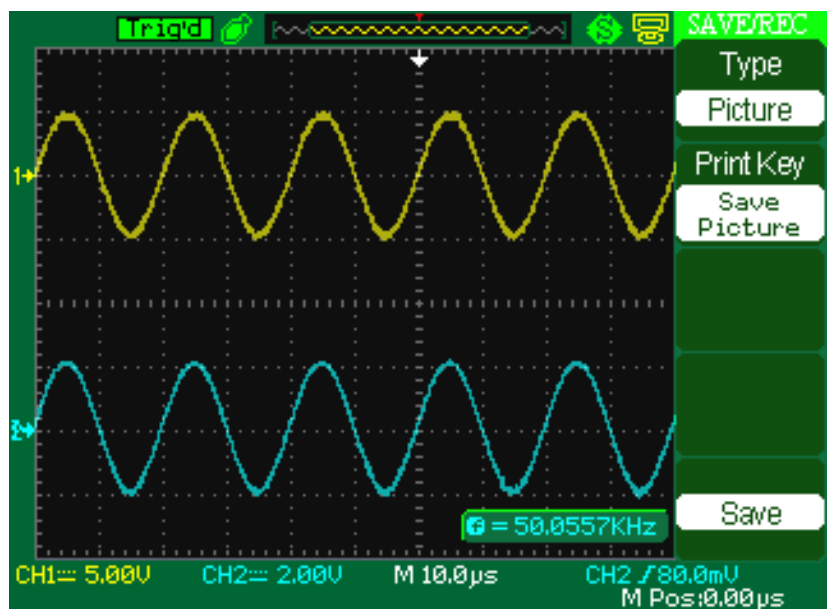

Figure 4: Serum (S1) based filter response-oscilloscope image

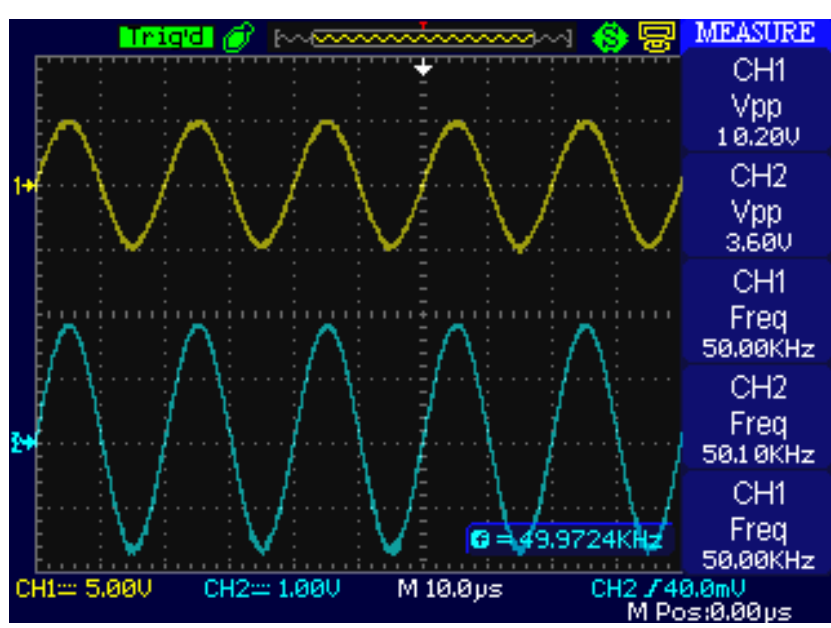

Figure 5: Serum (S1.2) based filter response-oscilloscope image 


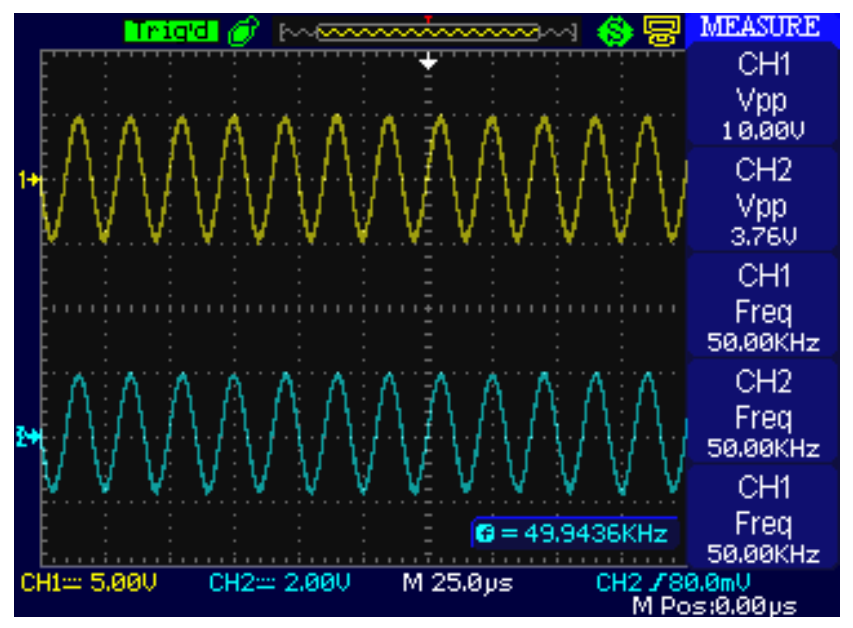

Figure 6: Serum (S1.5) based filter response-oscilloscope image

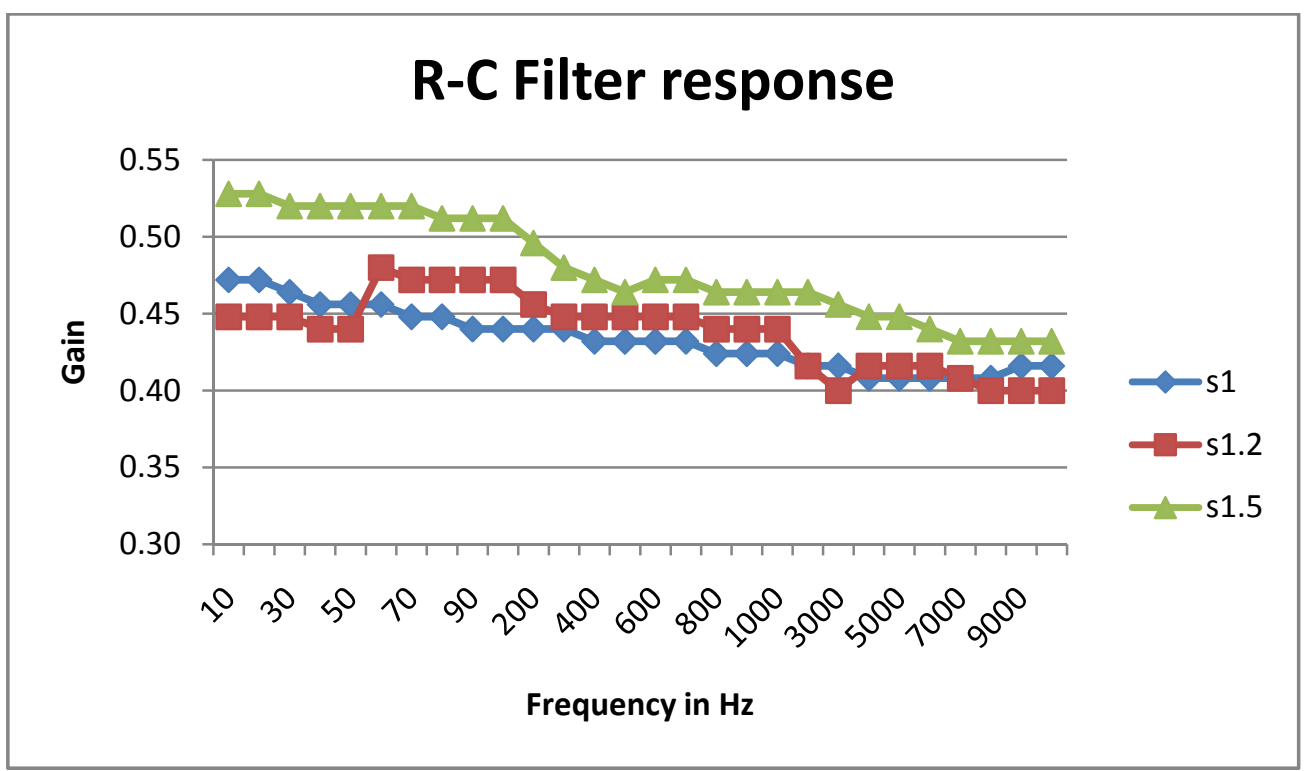

Figure 7: Serum based filter Gain vs Frequency response for $\mathrm{Hz}$ to $\mathrm{KHz}$ frequency range

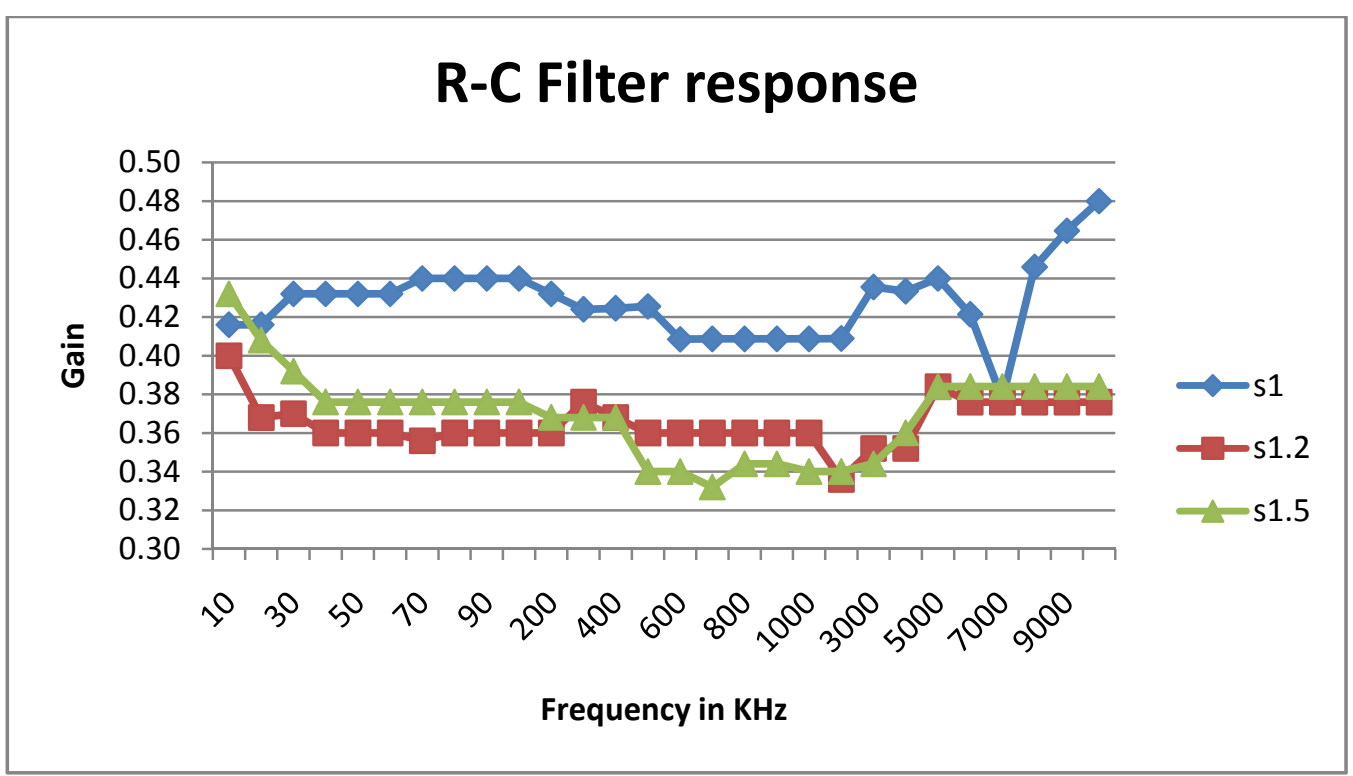

Figure 8: Serum based filter Gain vs Frequency response for $\mathrm{KHz}$ to $\mathrm{MHz}$ frequency range 


\section{VI.CONCLUSION}

Experiment's technique and results indicates the new way of electronics as well as alternative therapy for human disease detection and diagnostic. There may be a chance to use this bio-elctronics behaviour for disease healing purpose also. An idle filter has many other parameters which are not considered here as like many parameters that control serum construction is not taken care. The response indicates it is very dependent on applied frequency range. The signal shape is very close to its input signal that sounds like electronic filter. In short there will major two point we can conclude. One, an electronics behaviour may be obtained from human tissue itself. Secondly, bio-electronics characteristics may helpful to medical science for understanding and solving human diseases.

\section{ACKNOWLEDGMENT}

We are thankful to ECE department and CHARUSAT for providing us valuable recourses. We would like to extent our gratitude to Dr. S. P. Kosta for his motivation.

\section{REFERENCES}

[1] S. P. Kosta, et al. "Sea-water electronic circuits for salinity and temperature and pollution monitoring," J. of medicine and biomedical Sciences, vol. Nov 2010

[2] Shiv Prasad Kosta, Mukta Bhatele and Yogesh Prasad Kosta "New applications of human blood electronic circuits for disease healing," J. of medicine and biomedical sci.,August 2010.

[3] S. P. Kosta, Y.P. Kosta, Mukta Bhatele, et al. "Human blood liquid memristor," Int. J. of medical engineering and informatics, vol. 3, no. 1, pp. 16-29, 2011

[4] S. P. Kosta, et al. "Biomass champo leaf transistor configuration" Int. J. of biomechatronics and biomedical Robotics, vol. 1, no. 4, pp. 219-224, 2011

[5] S. P. Kosta, et al. "Novel applications of micro electrode-biological saline electrolyte interface at high sinusoidal current density" Int. J. of recent research and applied studies, vol. 81, no. 1, pp. 37-43, 2011

[6] Kosta, Shiv Prasad; Kosta, Y. P.; et al. "New vistas of electronics towards biological (biomass) sciences" Int. J. of academic research, vol. 3 no 1, pp. 511-526 January 2011

[7] S. P. Kosta, Mukta Bhatele, S. Purnima Nema, et al. "Physical model of human tissue skin-based electronic transistor, "Int. J. of biomechatronics and biomedical robotics, vol. 2, no 1, pp. 18-25, 2012

[8] S. P. Kosta, Mukta Bhatele, Jitendra Prasad Chaudhari, et al. "Human blood - based electronics transistor," Int. J. of medical engineering and informatics, vol. 4, no. 4, pp. 373-386, 2012

[9] Shiv Prasad Kosta, Y P Kosta, Mukta Bhatele, et al. "Bio-logical human tissue based electronic circuits - An alternate to drug therapy for sick-man (a perspective visionary concept)," J bioengineer \& biomedical sci., vol. 3, issue 3, 2013

[10] Shiv Prasad Kosta, Manthan Manavadaria et al. "Human blood plasma-based electronic integrated circuit amplifier configuration," The J. of biomedical research, vol. 27, no. 4, October 2013

[11] Manthan S. Manavadaria, Vishal P. Tank, et al. "First step towards liquid state electronics through analysis of liquid resistivity in water and serum using different electrodes," IOSR J. of electronics and communication engineering, vol. 9, no. 4, pp. 7-10, August 2014

[12] Shivansh Dave and Manthan Manavadaria (2016, Nov.) Functional realization of electronic elements in liquid state: A Review introducing electronic characteristics in liquid state presented at Int. Conference on Electrical, Electronics, and Optimization Techniques. [online] Available: http://ieeexplore.ieee.org/document/7754741/

[13] Avaiable at: http://www.electronics-tutorials.ws/filter/filter_2.html as on March 20, 2017

\section{AUTHOR PROFILE}

M. S. Manavadaria, He has obtained his M. Tech. degree in Communication Engineering field from CSPIT, CHARUSAT, Changa and B.E. in EC field from DDIT, DDU, Nadiad, Gujarat. He has done his master's dissertation project as NFP-Intern at ITER-INDIA, Gandhinagar, Gujarat in 2010-11. Currently he is pursuing his Doctorate Degree course in Bio-Electronics area from CSPIT, CHARUSAT, Changa, Gujarat, INDIA. His main interested areas are Bio-Electronics, Liquid State Electronics, RF \& Microwave and Networking. At present he is working as assistant professor at EC Department, CSPIT, CHARUSAT, Changa.

Dr. S. P. Kosta He is a Space Scientist, an Electronic Engineer and an Educationist. He has published around 140 research papers in reputed journals in electronics. As the Principal Technical Officer and Deputy Project Director, he contributed significantly for the development of the first satellite of India (1975) and has held prestigious positions in the Government of India (ISRO, Ministry of IT and Vice-chancellor of Jabalpur University). Currently he is working as Director of Charusat Space Research and Technology Center (CSRTC), CHARUSAT.

V. P. Tank, He has obtained his M. E. degree in Communication Engineering field from L.D. Engineering College, GTU and B.E. in EC field from DDIT, DDU, Nadiad, Gujarat. He had worked as head of EC Department at Noble Engineering College, GTU, Junagadh in 2011-2012. At present he is working as assistant professor at EC Department, CSPIT, CHARUSAT, Changa. 